\title{
Southeast Asian diversity: first insights into the complex mtDNA structure of Laos
}

\author{
Martin Bodner ${ }^{1}$, Bettina Zimmermann ${ }^{1}$, Alexander Röck ${ }^{2}$, Anita Kloss-Brandstätter ${ }^{3}$, David Horst ${ }^{4}$, Basil Horst ${ }^{5}$, \\ Sourideth Sengchanh ${ }^{6}$, Torpong Sanguansermsri ${ }^{7}$, Jürgen Horst ${ }^{8}$, Tanja Krämer ${ }^{9}$, Peter M Schneider ${ }^{9}$, Walther Parson ${ }^{1^{*}}$
}

\begin{abstract}
Background: Vast migrations and subsequent assimilation processes have shaped the genetic composition of Southeast Asia, an area of close contact between several major ethnic groups. To better characterize the genetic variation of this region, we analyzed the entire mtDNA control region of 214 unrelated donors from Laos according to highest forensic quality standards. To detail the phylogeny, we inspected selected SNPs from the mtDNA coding region. For a posteriori data quality control, quasi-median network constructions and autosomal STR typing were performed. In order to describe the mtDNA setup of Laos more thoroughly, the data were subjected to population genetic comparisons with 16 East Asian groups.

Results: The Laos sample exhibited ample mtDNA diversity, reflecting the huge number of ethnic groups listed. We found several new, so far undescribed mtDNA lineages in this dataset and surrounding populations. The Laos population was characteristic in terms of haplotype composition and genetic structure, however, genetic comparisons with other Southeast Asian populations revealed limited, but significant genetic differentiation. Notable differences in the maternal relationship to the major indigenous Southeast Asian ethnolinguistic groups were detected.
\end{abstract}

Conclusions: In this study, we portray the great mtDNA variety of Laos for the first time. Our findings will contribute to clarify the migration history of the region. They encourage setting up regional and subpopulation databases, especially for forensic applications. The Laotian sequences will be incorporated into the collaborative EMPOP mtDNA database http://www.empop.org upon publication and will be available as the first mtDNA reference data for this country.

\section{Background}

Laos is the only landlocked country of Mainland Southeast Asia. Under Siamese control since the $18^{\text {th }}$ century, Laos became part of French Indochina in 1893 and gained full independence in 1954. The country was severely affected by the Vietnam War. In 1975, the Lao People's Democratic Republic was established. It has a population of almost seven million [1]. Southeast Asia is an area of close contact between several major ethnolinguistic groups: the Daic (Tai-Kadai), the Austro-Asiatic (including the Mon Khmer), the Sino-Tibetan (including Tibeto-Burmans and Han), the Hmong-Mien (Miao-Yao), the Austronesian and the Altaic. Migration

\footnotetext{
* Correspondence: walther.parson@i-med.ac.at

${ }^{1}$ Institute of Legal Medicine, Innsbruck Medical University, Müllerstrasse 44, Innsbruck, Austria

Full list of author information is available at the end of the article
}

and assimilation processes formed the genetic landscape of culturally separated ethnic groups living in the same geographic area [2-8]. Laos has an unusually high degree of human diversity [9]: more than 200 ethno-linguistic groups have been identified [1]. The population pattern is the result of vast movements in the last 2000 years, mainly from China to the southern lowlands. The highlands in the North and along the Annamite Cordillera are inhabited by minorities [2]. Laotian tribes have formerly been classified into three categories based on the ethno-linguistic family, the customary habitat and the type of agricultural production: Lao Lum ("lowlander") of the Tai-Kadai, Lao Thoeng/Teung/Kang ("mid- or uplander") of the Mon Khmer and Lao Sung/Song ("highlander") of the Sino-Tibetan and the HmongMien. This classification ceased in 1981 due to promotion of unity of the nation and changes in habitat and
C Biomed Central

() 2011 Bodner et al; licensee BioMed Central Ltd. This is an Open Access article distributed under the terms of the Creative Commons Attribution License (http://creativecommons.org/licenses/by/2.0), which permits unrestricted use, distribution, and reproduction in any medium, provided the original work is properly cited. 
agriculture [10]. The number of officially listed tribes varies: 68 prior to 1975, 47 in 1995 [11]. In 2000, an ethno-linguistic system of 49 groups was established [1]. In addition, the classification based on language and culture has some difficulties $[2,8,10,12]$. Genetic data from Laos are scarce. The great ethnic diversity specifies the requirements for a population sample. For forensic, population and phylogenetic purposes, it needs to cover the lineages that occur as comprehensive as possible. This is warranted by country-wide sampling. We examine the mtDNA composition of Laos for the first time, presenting a cross-sectional population sample of 214 individuals from throughout the country that was analyzed according to the highest forensic standards.

\section{Methods}

\section{MtDNA samples and DNA extraction}

220 blood samples were acquired from volunteers of both sexes from The Lao People's Democratic Republic. Total DNA was extracted from peripheral blood lymphocytes using automated standard protocols [13]. All donors gave their informed consent. Samples were fully anonymized. Ethical approval was obtained from the Lao People's Democratic Republic's National Ethics Committee for Health Research (No.89/NECHR). The donors' provinces of birth comprise 15 of the 17 provinces of Laos. Figure 1 shows the number of samples

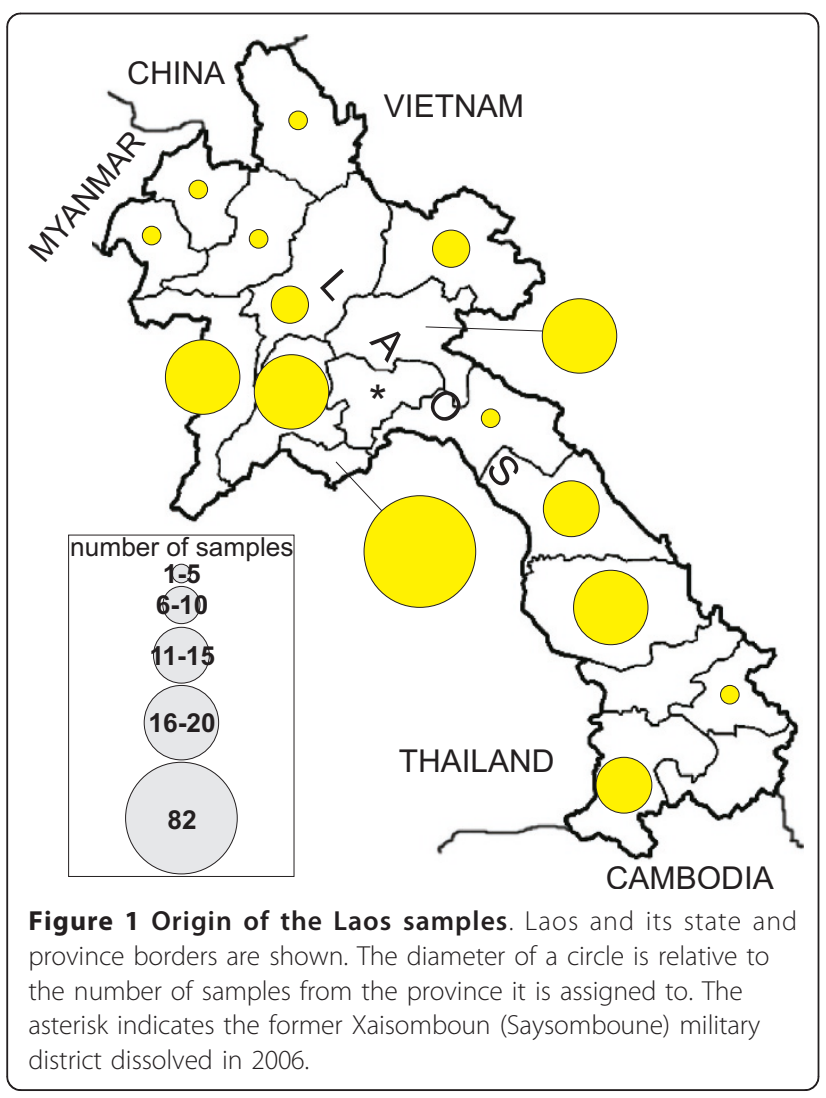

from each province. For a detailed list of donor provenience, see Additional file 1. No ethnic or linguistic affiliations are available. The dataset will support all genetic investigations regarding the total mtDNA variation found in Laos.

\section{MtDNA sequence analysis and haplogroup assignment}

We generated full mtDNA control region (CR) sequence data of 220 samples by chain termination sequencing. All experiments were performed according to the EMPOP forensic standard procedures to ensure highest sequence quality and reliable base calling [14]. Contiguous CR sequences were assembled, phylogenetically aligned [15] and reported with respect to the revised Cambridge Reference Sequence [16] using Sequencher V4.8 (Gene Codes Corporation).

We performed partial coding region ( $\operatorname{cod} R)$ sequencing in order to refine the phylogeny of samples that could not be assigned to a haplogroup more specific than paragroups $\mathrm{M}^{*}, \mathrm{~N}^{*}$ or $\mathrm{C}^{*}$. For samples of paragroup $\mathrm{M}^{*}$, we examined up to four segments (nps 18202450, nps 4450-5580, nps 8670-9850, nps 11450-12820) comprising SNPs diagnostic for M haplogroups, haplogroups D, G, and subhaplogroups. Samples of paragroup $C^{*}$ were inspected for their haplogroup $\mathrm{C} 4$ and C7 status by sequencing nps 5820-6660. This fragment was also used to test for B4 subhaplogroups and D5b1, where relevant. To detect haplogroups of paragroup $\mathrm{N}^{*}$, we analyzed nps 4450-5860 and nps 6340-7770. Primer sequences and experimental conditions were applied as published before [17]. To scrutinize samples for haplogroups C1c, G3b, L3b or M13, CR sequencing primer reads were extended upstream to $\mathrm{np} 15900$.

In order to endorse a reference haplogroup nomenclature, we used the comprehensive mtDNA "phylotree", release 8 [18], for assigning haplotypes to haplogroups according to their SNP pattern.

\section{Post sequencing data inspection}

A posteriori data quality control was performed using the NETWORK software provided on the EMPOP website (http://www.empop.org, $2^{\text {nd }}$ release) $[19,20]$. This program facilitates the inspection of rare or unobserved substitutions and indels occurring in the dataset that could represent possible sequence errors [21]. The resulting HVS-I and HVS-II networks are shown in Additional file 2 and explained in Additional file 3.

Identical haplotypes (disregarding cytosine insertions after nps 16193, 309 and 573 and point heteroplasmies) were inspected for maternal relatedness by typing up to 17 autosomal STR loci using the AmpFeSTR SGM Plus PCR Amplification Kit (Applied Biosystems) and the PowerPlex 16 System (Promega). Five samples were thereafter removed from the dataset, applying a cutoff 
likelihood ratio of 1000 [22]. One sample was excluded due to contamination.

\section{Population genetic analyses}

In order to shed light on the genetic structure and population genetic history of Laos and Southeast Asia, the Laos sample was compared to surrounding populations. Both countrywide and ethnic subpopulation samples from recent literature were compiled [3-7,12,17,23-26]. All sequences were aligned and trimmed to a greatest common range, cytosine insertions after nps 16193 and 309 were disregarded. We conducted two separate analyses, one comprising a total of 1229 samples from this study, Northern Thailand [17], Vietnam [23], Hong Kong [24] and a mixed Han sample [7] with a greatest common range of nps 16024-16497 and 30-407 (see Table 1), another comprising Laos and 16 East Asian populations with a total of 5470 samples (nps 16024-16383) (see Table 2).

The random match probability for each population was calculated as sum of squared haplotype frequencies (disregarding cytosine insertions after nps 16193, 309 and 573). We performed intra- and interpopulation comparisons: the number of mean pairwise differences within and between populations, molecular diversity indices, and an analysis of molecular variance (AMOVA) were calculated using Arlequin (version 3.5.1.2) [27]. Also the corrected numbers of MPD between populations were determined, i.e. the MPD between two populations minus the mean number of MPD contained within these two populations. To give additional perspective on the genetic relation of the populations and for a visualization of the AMOVA results, we performed a correspondence analysis based on pairwise $\mathrm{F}_{S T}$ values using PASW Statistics 18 (SPSS Inc.).

\section{Results and Discussion \\ Haplogroup composition, unique and most common haplotypes of the Laos sample}

The 214 Laotian samples classified into 64 distinct haplogroups [18]. $45 \%$ of the samples were assigned to a terminal twig of the "phylotree". 171 CR haplotypes, of which 141 were unique (66\% of the samples) were detected (disregarding indels around nps 16193, 309 and 573). The most prevalent haplogroups were B5a (12\%), F1a1a (7.5\%), C7 and M7b1 (6\% each). The most frequent CR haplotypes (five occurrences each) were a B5a (73-210-263-315.1C-523del-524del-16140-16183C16189-16266A-16519) and a F1a1 haplotype (73-249del263-315.1C-523del-524del-16129-16162-16172-1630416399-16519).

Macrohaplogroup N (including haplogroups A, B, F, N and R) comprised $57 \%$ of the samples in 37 haplogroups. $26 \%$ of the samples were assigned to haplogroup B, almost equally to B4 and B5. 26 out of the 27 haplogroup B5 samples were found to be haplogroup B5a. $22 \%$ of the samples belonged to haplogroup F, of which $79 \%$ belonged to F1a and its subhaplogroups. Macrohaplogroup M (including haplogroups C, D, G and M) comprised $43 \%$ in 27 haplogroups. $32 \%$ of the samples belonged to haplogroup $M$, distributed among ten subhaplogroups. $25 \%$ of the M samples, however, remained $M^{*}$. No maternal west Eurasian or African admixture was detected.

Figure 2 depicts a phylogenetic tree of all haplogroups and their absolute frequencies. A haplogroup and frequency list is given in Table 3. The analyzed range, haplotype and haplogroup of every sample are available from Additional file 4.

\section{Diversity indices of the Laos sample}

The power of discrimination by $\mathrm{CR}$ was calculated $99.26 \%$, the random match probability $0.74 \%$. The number of mean pairwise differences for full CR was $13.14 \pm$ 5.94. This high number is due to the double origin of East Asian mtDNA lineages in both macrohaplogroup $\mathrm{M}$ and $\mathrm{N}$.

\section{Point heteroplasmic positions in the Laos sample}

Point heteroplasmies at a single CR position were observed in eight samples. Two of these (16093Y and 152Y) were the most common point heteroplasmic positions observed in a dataset of 5015 global samples [28]. One position (16261Y) was found three times, two positions a single time (16289R and 16468Y), three heteroplasmic positions

Table 1 Diversity measures of the Laos sample and four other East Asian populations (HVS-I and HVS-II)

\begin{tabular}{llllll}
\hline Population statistics & Laos & Northern Thailand & Vietnam & Hong Kong & Mixed Han \\
Reference & This study & Zimmermann 2009 [17] & $\begin{array}{l}\text { Irwin 2008 [23] } \\
\text { Irwin 2009 [24] }\end{array}$ & Yao 2002 [7] \\
\hline Number of samples & 214 & 190 & 187 & 376 & 262 \\
Proportion of haplotypes & 0.79 & 0.74 & 0.83 & 0.80 & 0.94 \\
Proportion of unique haplotypes & 0.64 & 0.58 & 0.73 & 0.69 & 0.89 \\
Mean pairwise differences & $10.932+/-4.990$ & $10.790+/-4.932$ & $10.620+/-4.859$ & $10.652+/-4.862$ & $10.964+/-5.000$ \\
RMP & 0.008 & 0.011 & 0.009 & 0.005 & 0.004 \\
\hline
\end{tabular}

Total $\mathrm{N}=1229$, nps 16024-16497 30-407. 
Table 2 Diversity measures of the Laos sample and 16 other East Asian populations (HVS-I)

\begin{tabular}{|c|c|c|c|c|c|c|}
\hline $\begin{array}{l}\text { Population statistics } \\
\text { Reference }\end{array}$ & $\begin{array}{l}\text { Laos } \\
\text { This study }\end{array}$ & $\begin{array}{c}\text { Northern Thailand } \\
\text { Zimmermann } 2009 \\
{[17]}\end{array}$ & $\begin{array}{c}\text { Vietnam } \\
\text { Irwin } 2008 \text { [23] }\end{array}$ & $\begin{array}{c}\text { Hong Kong } \\
\text { Irwin } 2009 \text { [24] }\end{array}$ & $\begin{array}{l}\text { Austro-Asiatic } \\
\text { Li } 2007 \text { [3] }\end{array}$ & $\begin{array}{c}\text { Daic } \\
\text { Li } 2007 \text { [3] }\end{array}$ \\
\hline Number of samples & 214 & 190 & 187 & 376 & 124 & 772 \\
\hline Proportion of haplotypes & 0.68 & 0.65 & 0.73 & 0.65 & 0.57 & 0.45 \\
\hline $\begin{array}{l}\text { Proportion of unique } \\
\text { haplotypes }\end{array}$ & 0.53 & 0.50 & 0.59 & 0.51 & 0.38 & 0.31 \\
\hline $\begin{array}{l}\text { Mean pairwise } \\
\text { differences }\end{array}$ & $7.686+/-3.597$ & $7.498+/-3.518$ & $7.353+/-3.455$ & $7.291+/-3.421$ & $6.842+/-3.243$ & $6.558+/-3.103$ \\
\hline RMP & 0.012 & 0.015 & 0.011 & 0.008 & 0.023 & 0.01 \\
\hline Population statistics & Pinghua Han & $\begin{array}{l}\text { Southern Indig. } \\
\text { Minorities }\end{array}$ & Tibet & $\begin{array}{c}\text { Southern Tibeto- } \\
\text { Burman }\end{array}$ & Guangdong Han & Mixed Han \\
\hline Reference & Gan 2008 [12] & Gan 2008 [12] & Wen 2004 [4] & Wen 2004 [4] & Chen 2008 [25] & Yao 2002 [7] \\
\hline Number of samples & 197 & 273 & 91 & 405 & 106 & 262 \\
\hline Proportion of haplotypes & 0.71 & 0.58 & 0.69 & 0.69 & 0.89 & 0.87 \\
\hline $\begin{array}{l}\text { Proportion of unique } \\
\text { haplotypes }\end{array}$ & 0.54 & 0.42 & 0.47 & 0.53 & 0.80 & 0.79 \\
\hline $\begin{array}{l}\text { Mean pairwise } \\
\text { differences }\end{array}$ & $7.918+/-3.697$ & $7.536+/-3.529$ & $6.317+/-3.024$ & $7.759+/-3.621$ & $7.178+/-3.392$ & $7.620+/-3.566$ \\
\hline RMP & 0.012 & 0.018 & 0.02 & 0.007 & 0.013 & 0.006 \\
\hline Population statistics & Hmong & Mien & Northern Han & Southern Han & $\begin{array}{c}\text { Island South East } \\
\text { Asians }\end{array}$ & \\
\hline Reference & Wen 2005 [5] & Wen 2005 [5] & Wen $2004[6]$ & Wen 2004 [6] & Hill 2007 [26] & \\
\hline Number of samples & 167 & 370 & 238 & 473 & 1025 & \\
\hline Proportion of haplotypes & 0.63 & 0.51 & 0.82 & 0.74 & 0.40 & \\
\hline $\begin{array}{l}\text { Proportion of unique } \\
\text { haplotypes }\end{array}$ & 0.50 & 0.36 & 0.74 & 0.63 & 0.27 & \\
\hline $\begin{array}{l}\text { Mean pairwise } \\
\text { differences }\end{array}$ & $6.269+/-2.991$ & $6.574+/-3.113$ & $6.860+/-3.240$ & $7.407+/-3.469$ & $6.716+/-3.170$ & \\
\hline RMP & 0.022 & 0.016 & 0.009 & 0.005 & 0.012 & \\
\hline
\end{tabular}

Total $\mathrm{N}=5470, \mathrm{nps} 16024-16383$.

(16086Y, 16179Y, 16271Y) were absent in the 5015 samples. A search in the 10970 sequences (including most of the 5015) of the EMPOP database (http://www.empop.org, $2^{\text {nd }}$ release) yielded three hits for $16086 \mathrm{Y}$, the latter two positions remained unobserved. The proportion of CR profiles revealing a heteroplasmic position was $3.7 \%$, in agreement with observations in blood samples from other populations (1-9.5\%) [28].

New insights into the Southeast Asian mtDNA phylogeny After CR sequencing, a number of Laos samples displayed new SNP motifs within haplogroups B and D that were found recurrent in other Central, East and Southeast Asian populations (Thailand, Vietnam, Hong Kong, Uzbekistan, Japan and the Miao) [17,23,24,29-31]. These findings (see Table 4 and Additional file 5) indicate that the phylogeny of the particular lineages is not yet fully resolved.
The partial codR sequencing had a great impact on the phylogenetic resolution of the dataset. It helped to confirm and exclude haplogroups without or with recurrent CR motifs. In addition, new codR SNP patterns were detected. The assays applied therefore constitute valuable time-, cost- and DNA-saving alternatives to whole mitochondrial genome sequencing for phylogenetic purposes.

The paragroup $M^{*} \operatorname{cod} R$ sequencing assay was performed on 41 samples. 14 samples were confirmed to belong to a described $M$ haplogroup, haplogroups D or G. New, recurrent SNP motifs with matching haplotypes from Thailand, Vietnam, Hong Kong and the Philippines $[[17,23,24,32]$ and P.M. Schneider, personal communication] were revealed by all but two of the remaining $M^{*}$ samples. Figure 3 shows the novel $M$ lineages found. To remain with the established nomenclature [18], we refrained from assigning new haplogroup names. For some 


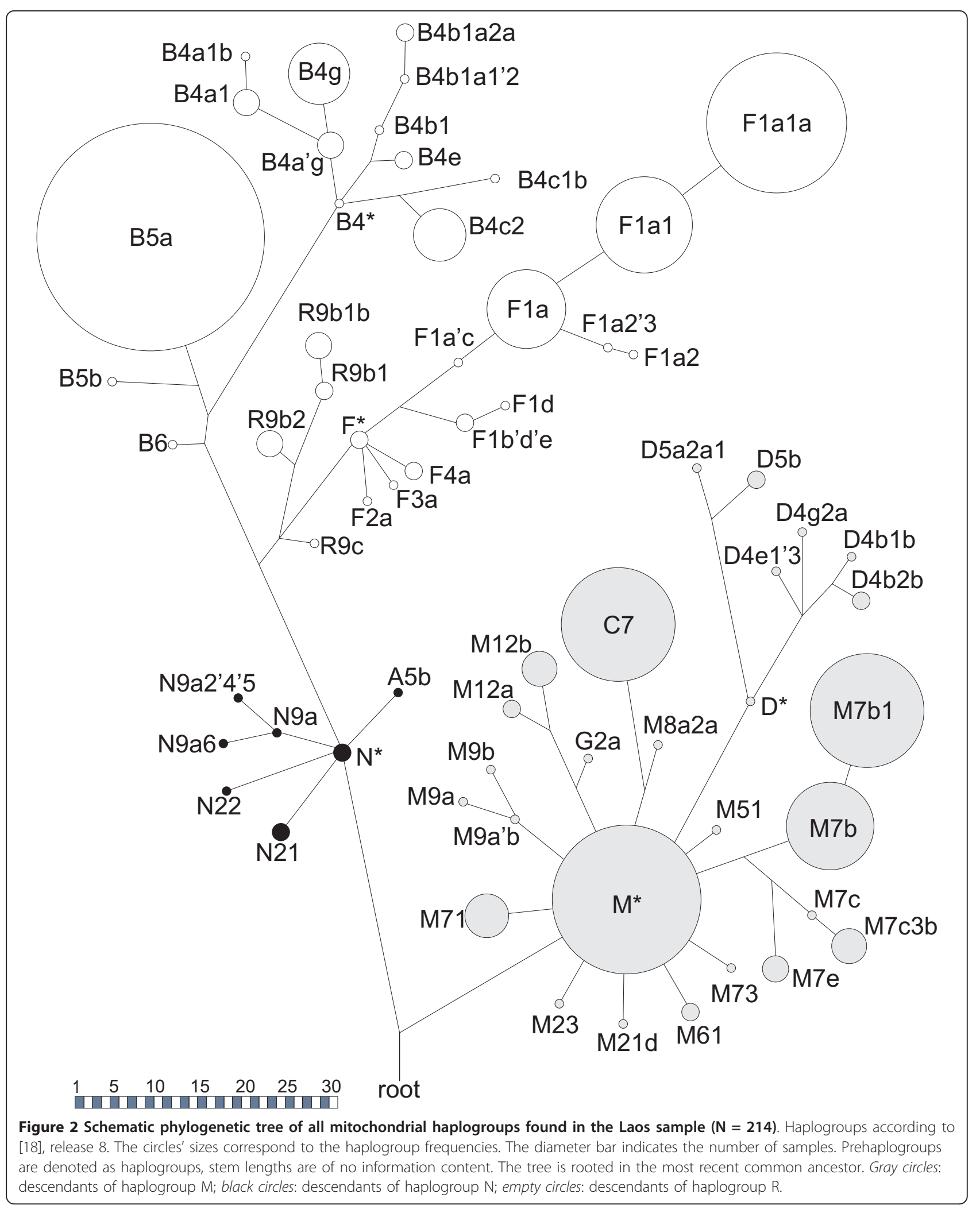


Table 3 MtDNA haplogroup frequencies within 214 samples from Laos

\begin{tabular}{|c|c|c|}
\hline Haplogroup & $\mathrm{N}$ & Frequency (\%) \\
\hline$A 5 b$ & 1 & 0.5 \\
\hline$B 4^{*}$ & 1 & 0.5 \\
\hline B4a'g* & 3 & 1.4 \\
\hline $\mathrm{B} 4 \mathrm{a} 1^{*}$ & 3 & 1.4 \\
\hline B4a1b & 1 & 0.5 \\
\hline B4b1* & 1 & 0.5 \\
\hline B4b1a1'2* & 1 & 0.5 \\
\hline B4b1a2a & 2 & 0.9 \\
\hline$B 4 c 1 b$ & 1 & 0.5 \\
\hline B4C2 & 6 & 2.8 \\
\hline B4e & 2 & 0.9 \\
\hline B4g & 7 & 3.3 \\
\hline B5a & 26 & 12.1 \\
\hline B5b & 1 & 0.5 \\
\hline B6 & 1 & 0.5 \\
\hline $\mathrm{C} 7$ & 13 & 6.1 \\
\hline$D^{*}$ & 1 & 0.5 \\
\hline D4b1b & 1 & 0.5 \\
\hline D4b2b & 2 & 0.9 \\
\hline D4e1'3 & 1 & 0.5 \\
\hline D4g2a & 1 & 0.5 \\
\hline preD5a2a1 & 1 & 0.5 \\
\hline D5b & 2 & 0.9 \\
\hline$F^{*}$ & 2 & 0.9 \\
\hline $\mathrm{F} 1 \mathrm{a}^{\prime} \mathrm{c}^{*}$ & 1 & 0.5 \\
\hline F1a* & 9 & 4.2 \\
\hline F1a1* & 11 & 5.1 \\
\hline F1a1a & 16 & 7.5 \\
\hline F1a2 & 1 & 0.5 \\
\hline F1a2' $3^{*}$ & 1 & 0.5 \\
\hline F1b'd'e* & 2 & 0.9 \\
\hline F1d & 1 & 0.5 \\
\hline $\mathrm{F} 2 \mathrm{a}$ & 1 & 0.5 \\
\hline F3a & 1 & 0.5 \\
\hline $\mathrm{F} 4 \mathrm{a}$ & 2 & 0.9 \\
\hline G2a & 1 & 0.5 \\
\hline$M^{*}$ & 17 & 7.9 \\
\hline$M 7 b^{*}$ & 10 & 4.7 \\
\hline M7b1 & 13 & 6.1 \\
\hline$M 7 c^{*}$ & 1 & 0.5 \\
\hline M7c3b & 4 & 1.9 \\
\hline M7e & 3 & 1.4 \\
\hline M8a2a & 1 & 0.5 \\
\hline M9a'b* & 1 & 0.5 \\
\hline M9a & 1 & 0.5 \\
\hline M9b & 1 & 0.5 \\
\hline M12a & 2 & 0.9 \\
\hline M12b & 4 & 1.9 \\
\hline M21d & 1 & 0.5 \\
\hline preM23 & 1 & 0.5 \\
\hline
\end{tabular}

Table 3 MtDNA haplogroup frequencies within 214 samples from Laos (Continued)

\begin{tabular}{lll}
\hline M51 & 1 & 0.5 \\
preM61 & 2 & 0.9 \\
M71 & 5 & 2.3 \\
M73 & 1 & 0.5 \\
$\mathrm{~N}^{*}$ & 2 & 0.9 \\
N9a* & 1 & 0.5 \\
N9a2'4'5 & 1 & 0.5 \\
N9a6 & 1 & 0.5 \\
preN21 & 2 & 0.9 \\
N22 & 1 & 0.5 \\
R9b1* & 2 & 0.9 \\
R9b1b & 3 & 1.4 \\
R9b2 & 3 & 1.4 \\
R9c & 1 & 0.5 \\
\hline
\end{tabular}

Haplogroups according to [18], release 8. Frequencies are rounded to one decimal place.

haplotypes, codR SNPs that were not analyzed were inferred from the known information. This strategy is widely applied when CR is only sequenced partly $[4,5,7]$, and in genetic epidemiology ("imputing").

The recently described haplogroup M71 was diverse in the Laos sample. Several new sublineages (including the postulated "M71a1" [32]) could be identified in 23 individuals from Laos, Thailand, Vietnam, China and the Philippines. Three haplogroup M samples from Laos and Thailand revealed the SNP pattern 11810-1273216362 indicating haplogroup M61 [33], while other presumably diagnostic SNPs were not present. These findings indicate that the Southeast Asian mtDNA phylogeny is far from being resolved and needs more sequence information for full clarification (see Figure 3).

We inspected the recurrent codR SNPs for their effect on amino acid level using the "MitoWheel" v1.2 http://www. mitowheel.org. Interestingly, two out of the 11 base substitutions caused amino acid substitutions (valine-isoleucine and vice versa), while nine were silent mutations. SNP variants persistent in the face of purifying selection are expected to be silent, adaptive or neutral (by affecting weakly conserved amino acids or causing substitutions by similar amino acids, as encountered here) [34]. This finding

Table 4 Novel haplogroup B and D mtDNA CR SNP motifs found recurrent in Laos and other Asian populations

\begin{tabular}{lcc}
\hline Haplogroup & Additional CR motif & Found in Laos and \\
\hline B4 & 183-310-374-16274-16289-16301 & {$[23]$} \\
B4g & 61 A-62-16181C-16213 & {$[29]$} \\
B6 & 234 & {$[23]$} \\
D & 247 & {$[17]$} \\
D4g2a & @195 & {$[17,30]$} \\
\hline
\end{tabular}

Haplogroups according to [18], release 8 . 


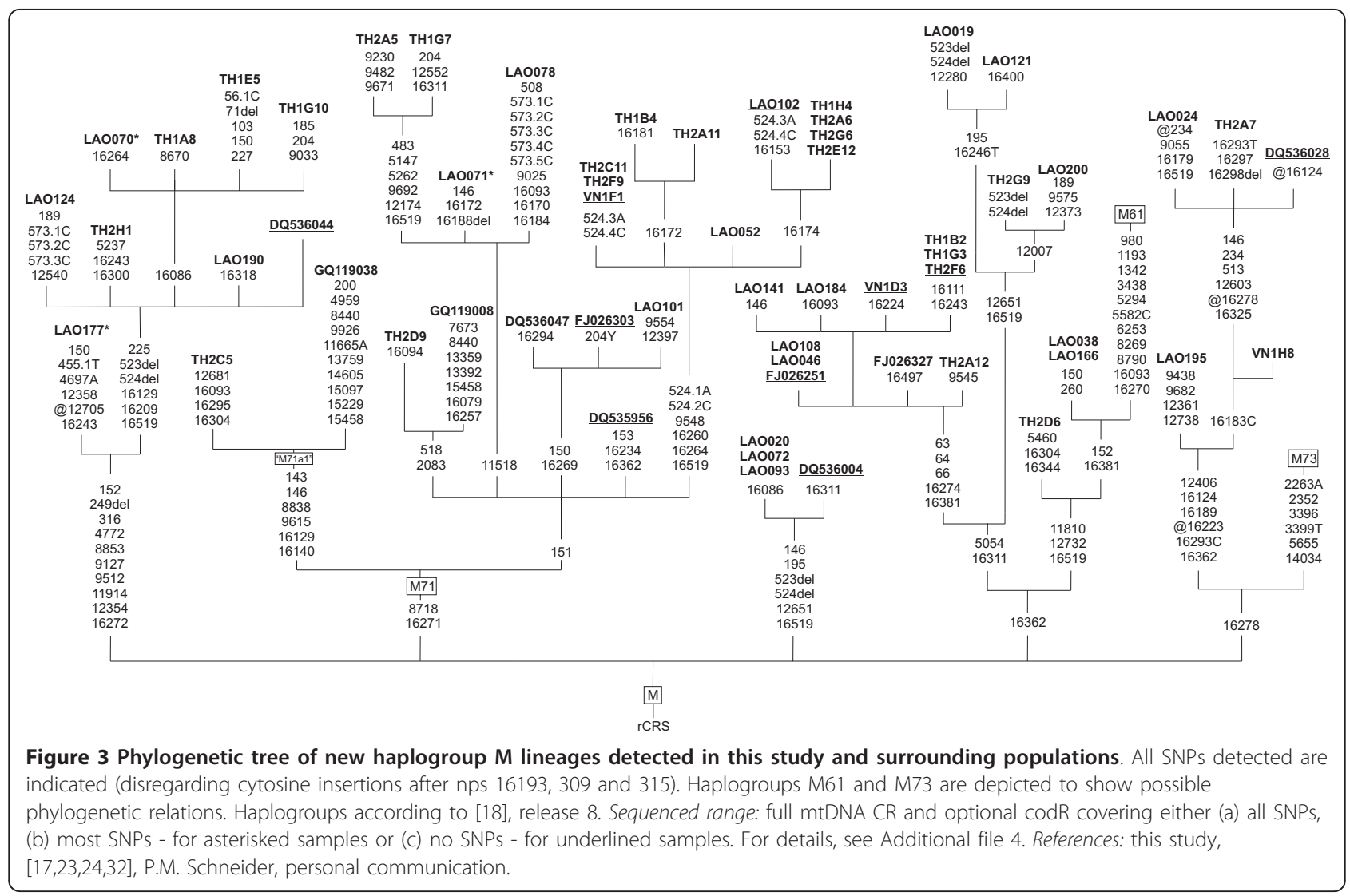

could be another indication of a true phylogenetic meaning of the new basal haplogroup M codR SNP patterns that we found in multiple samples from several populations.

\section{Haplogroup composition of Laos compared to surrounding populations}

The Laos sample showed mtDNA diversity characteristic of Southeast Asian populations. The composition of haplogroups was in agreement with other populations from this region [3-7,12,17,23-25,35], with haplogroups $B 4 a$, B5a, M7b1, F1a and R9 being the most frequent southern aboriginal lineages. The ample haplogroup pattern may reflect the rich history of migrations of ethnic groups in today's Laos. Aside from a few haplogroups with high sample numbers, a plethora was present at very low frequencies. The five most prevalent haplogroups together comprised $37 \%$ of the samples (see Table 3).

In Laos, haplogroups B4a and R9 were less frequent than expected from the literature. This is partly explained by "technical" reasons: samples assigned to haplogroup "R9a" by HVS-I-motifs $[4,12]$ actually belong to F3a (R9a is discontinued). Nevertheless, there was only one F3a sample in the Laos dataset. Earlier publications considered $\mathrm{B} 4 \mathrm{~g}$ haplotypes as $\mathrm{B} 4 \mathrm{a}$ due to their common root $[3,5,7,12,23,35]$. B4g, not $\mathrm{B} 4 \mathrm{a}$ is the most prevalent B4 haplogroup in Laos.
Little Northern contribution was detected. The presence of haplogroups described as Northern (East) Asian $[4,6,7,25,36]$, i.e. A, Z, Y, C, M8a, M9, G2, D and N9, was low in the Laos dataset. Haplogroups G, M8 and $\mathrm{A}$ were present as singletons, $\mathrm{Y}$ and $\mathrm{Z}$ were absent. Haplogroup $C$, in contrast, showed an unexpectedly high frequency of $6 \%$, but very limited diversity: all haplotypes belonged to haplogroup C7. Interestingly, 12 of the 13 samples derive from Northern provinces (see Additional file 1). Together with the singular presence of haplogroup M8, this is indicative of a founder effect possibly the immigration of a small group of females carrying the C7 haplogroup from its Northern pool.

\section{Genetic comparisons with four East Asian populations (HVS-I and HVS-II)}

We compared the genetic composition of the current sample to that of populations from Thailand [17], Vietnam [23], Hong Kong [24] and mixed Han from China and Taiwan [7] with the greatest common range of nps 16024-16497 and 30-407. The total number of samples was 1229 (see Table 1).

The numbers of intrapopulation MPD were highly similar. The highest intrapopulation diversity was found in the mixed Han sample (10.96) followed by Laos (10.93); the lowest in Vietnam (10.62). The intrapopulation RMP 
ranged between 0.004 (Han) and 0.011 (Thailand) indicating that the populations were highly differentiated. Laos was intermediate with a value of 0.008 (see Table 1). Interpopulation MPD ranged from 10.68 (Vietnam-Hong Kong) to 11.18 (Laos-Han), the corrected values from 0 (Laos-Vietnam) to 0.23 (Laos-Han). The low and similar values indicate similar genetic structures of the populations. The corrected and uncorrected results corresponded, as population pairs ranked low, medium or high in both calculations (see Additional file 6).

All populations shared haplotypes to varying extents. 47 haplotypes $(28 \%)$ of the Laos sample were found in the other populations. Thailand was at the top (16\% shared haplotypes) followed by Vietnam (12\%) and Hong Kong (8\%). The mixed Han sample only shared $3 \%$ of its haplotypes with Laos and its most frequent shared haplotype was only a singleton in the Laos sample (see Additional file 7).

AMOVA was used to test for significant variation in the mtDNA genetic structure among the populations. Almost all genetic variation observed is attributable to differences within populations (99.16\%). Variance among populations only accounts for $0.84 \%$. The AMOVA results were statistically significant (see Additional file 6).

The low and similar pairwise $F_{S T}$ values possibly reflect the common origin of the populations and little evolutionary time since their differentiation. However, the small genetic variance detected was significant for almost all comparisons. No significant difference in genetic structure was found between the Laos and the Vietnam population sample, which may indicate extensive gene flow by migration between the two countries (see Additional file 6).

\section{Genetic comparisons with 16 East Asian populations (HVS-I)}

To shed more light on the genetic structure of the Laos sample, we performed analogous analyses including a greater number of East Asian populations [3-7,12,17,23-26] with a shorter segment (nps 16024-16383). The total number of samples was 5470 from 17 populations (see Table 2).

The numbers of intrapopulation MPD ranged from 6.27 to 7.92 . The highest intrapopulation diversity was found in the Pinghua Han [12] (confirming their genetically heterogeneous background), the lowest in the Hmong [5]. Laos was third highest (7.69). The intrapopulation RMP ranged from 0.005 (Southern Han [6]) to 0.023 (Austro-Asiatic [3]) indicating highly differentiated populations. Laos was intermediate at 0.012 (see Table 2).

The interpopulation MPD spanned from 6.47 (Hmong [5]-Daic [3]) to 7.90 (Southern Tibeto-Burmans [4]Pinghua Han [12]), the corrected values from 0 (even arithmetical values below zero) for several comparisons to 0.74 (Laos-Tibet [4]). The range of values was greater than for the analyses using a longer segment (see previous section), revealing a greater population differentiation. This was expected given the broader geographic origin of populations included. Tibet, being a population at far geographic distance, had the highest numbers of MPD with all of the samples but the other Northern sample (Northern Han [6]), an effect that was only visible after correction (see Additional file 8).

The order of the populations in the MPD and RMP analyses was different when only HVS-I was analyzed (see previous section), which demonstrates the impact of larger reading frames. It can be supposed that the results of analyses with more information included are closer to truth.

All populations shared haplotypes with the Laos sample. $46 \%$ of the Laos haplotypes were found in other populations. This high percentage is due to the short mtDNA segment and the high number of populations involved. The geographically closer populations, i.e. Thailand [17], Hong Kong [24], the Southern Indigenous Minorities [12], Pinghua Han [12], Guangdong Han [25], Vietnam [23], Hmong and Mien [5] and the AustroAsiatic [3] tended to share higher proportions (13-30\%) than the Southern Tibeto-Burmans and Tibet [4], Daic [3], the mixed Han samples [6,7] and the sample from Island Southeast Asia [26] (3-9\%) (see Additional file 7).

AMOVA again showed that the observed genetic variation was mainly attributable to differences within populations $(98.09 \%)$. Variance among populations accounted for $1.91 \%$ (see Additional file 8). The AMOVA results were statistically significant.

Mainly low, but also some intermediate $\mathrm{F}_{S T}$ values resulted from the pairwise comparisons, indicating limited genetic differentiation between the populations (as in the previous section). All intermediate $\mathrm{F}_{S T}$ values were yielded in comparisons including the Tibet [4] or the Northern Han [6] sample, and comparisons with these two population samples resulted in the highest pairwise $F_{S T}$ values for most other groups. The outlier position of the two Northern samples detected in several genetic comparisons supports the concept of isolation by geographic distance with subsequent differentiation.

Most differences in genetic structure were highly significant. Only the mixed Han sample [7] and the Pinghua Han [12] with multi-ethnic origin showed no significant difference in several comparisons, along with the Laos sample when compared to the Vietnam sample [23], as shown in the previous section (see Additional file 8).

An MDS plot for visualization of the AMOVA results is depicted in Figure 4. The positioning of the samples did not change when nonsignificant $\mathrm{F}_{S T}$ values (see Additional file 8) were excluded. In this correspondence analysis, the population sample from Laos clustered with the samples from Vietnam [23] and Thailand [17] 


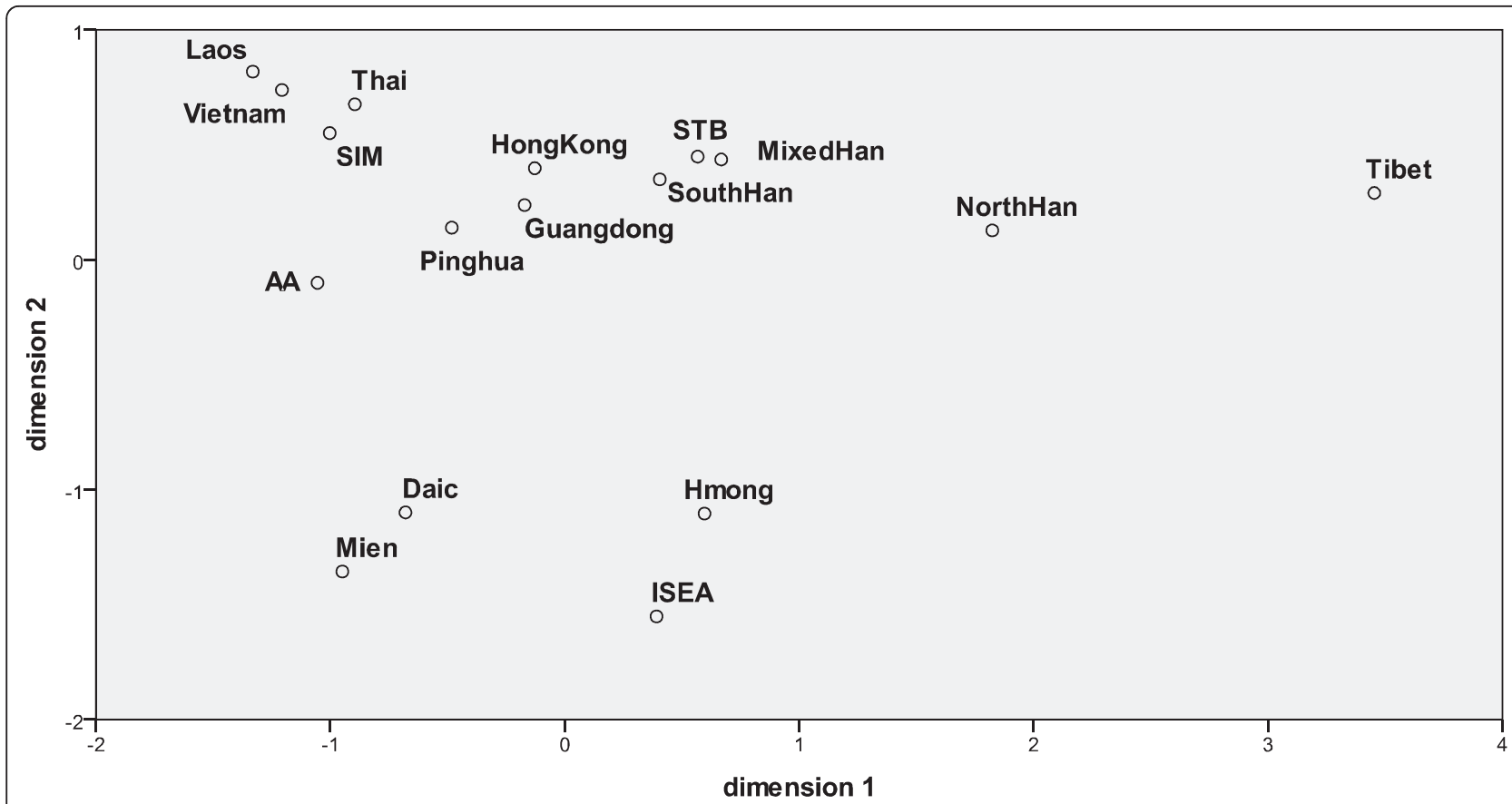

Figure 4 Multidimensional scaling analysis of genetic distances between 17 population samples from East Asia. Computed from $F_{S T}$ indices based on nps 16024-16383 (see Additional file 8). Stress value: 0.085. Abbreviations: AA - Austro-Asiatic, ISEA - Island Southeast Asians, SIM - Southern Indigenous Minorities, STB - Southern Tibeto-Burmans. References: [3-7,12,17,23-26].

and the Southern Indigenous Minorities [12]. This might be explained by the fact that these four samples do not represent ethnic entities, but are a similar combination of several groups. The partly shared political history of the three neighboring countries could have facilitated migrations.

The other populations appeared more distant from the Laos sample: the Austro-Asiatic [3] and the cluster of the Guangdong Han [25], Pinghua Han [12] and the sample from Hong Kong [24] were closer, the cluster of Southern Han [6], Mixed Han [7] and Southern TibetoBurmans [4] at an intermediate distance, while the remaining groups, i.e. the Hmong and Mien [5], the Daic [3], the Northern samples (Northern Han [6], Tibet [4]) as well as the Island Southeast Asians [26] localized further away.

Obviously, the Han population samples did not cluster in the correspondence analysis. Although assigned to the same nationality, they are distant from each other genetically. The mixed Han [7] localized between the Northern and Southern Han [6] - as expected near their sister Sino-Tibetan branch, the Southern Tibeto-Burman sample [4] - while the Pinghua [12] and the Guangdong [25] Han samples with minority background and the sample from Hong Kong [24] clustered between the other Southeast Asian populations rather than with the other Han samples. This reflects the process of assimilation of indigenous populations along with the Han expansion $[12,25]$ and the particular genetic composition of Hong Kong [24] possibly caused by a history distinct from the rest of today's China. Our findings further point out the importance of subdatasets even for large ethnic groups, as reported before [6,7]. It was also meaningful to separate the Hmong and Mien population samples [5], that are usually combined based on linguistics, as they differ genetically (see Figure 4).

\section{Understanding the genetic history of Laos}

The rapid initial colonization of Southeast Asia at some time after $60 \mathrm{kYBP}$ along the "Southern Coastal Route" was followed by an expansion in situ (while other groups moved on), a dispersal into the continent and onto the islands, and the subsequent differentiation of ethnic groups with common origin but diverging lineages (most of which arose during the last stadial of the Würm glacial, 30-10 kYBP, probably in different refugia) $[3,7,26,37,38]$. We confirmed this in our analyses: the novel basal $M$ haplogroups found in high diversity in the Laos sample and surrounding populations support the fast migration and in situ differentiation model (see Figure 3). Despite of little evolutionary time, the linguistically separated groups also clearly differed genetically (see Figure 4).

The original genetic structure of MSEA with distinct areas inhabited by the main ethnic groups - the Daic in the coastal areas of the Southeast, the Austro-Asiatic in Western and central MSEA, the Sino-Tibetan (Tibeto- 
Burmans and Han) in the North and the Hmong-Mien in today's central China - has been blurred by massive migrations [3,7]. In the past 2600 years, the TibetoBurmans moved from the Northwest and the Himalayan area to the South, absorbing indigenous lineages [4]. In the past 2000 years, several waves of Han expansions to the West and South caused massive displacements of indigenous minorities $[3,4,6,7]$. The Daic were forced southward by the expanding Han in a fanning spread and are now mainly found west of Hong Kong. In today's Laos, they formed small city states in the North from the late $11^{\text {th }}$ century $\mathrm{AD}$ and later moved to the central and Southern plains, thereby repelling the Austro-Asiatic population to the highlands or assimilating them. Today, the Daic "lowlander" living in the plains and along the rivers constitute the major proportion $(60-65 \%)$ of the Laos population. They are dominant in language, culture, media and politics [1-3,6,10,39]. The Hmong-Mien are the newest arrival: they were continuously forced to the Southwestern areas already settled by Austro-Asiatic and Southern Tibeto-Burmans. They immigrated to the hilly North of Laos only in the past several hundred years and today exhibit a pattern of refuge ("highlander"), rather than a positive expansion $[2,5,8]$.

Traces of these migrations might be visible in the extant mtDNA composition of Laos. To shed more light on the population genetic history, it was meaningful to compare the cross-sectional Laos sample to those of the ethnic groups that together constitute the population of this country.

An interesting picture was revealed (see Additional Files 6, 7 and 8, Figure 4): the ethnic population with the highest similarity to the Laos sample in terms of shared haplotypes, MPD, pairwise $\mathrm{F}_{S T}$ values and localization in the MDS plot were the Austro-Asiatic [3]. This was unexpected, as the "midlander" only constitute $20-25 \%$ of the Laotian population, being the major group only in some regions $[10,39]$. Given the fact that the Daic sample [3] localized at much further distance from the Laos sample in the correspondence analysis (see Figure 4), had a higher corrected MPD value and less shared haplotypes, our findings indicate a great proportion of assimilated Austro-Asiatic lineages in the Daic-dominated Laos.

The ethnic samples second closest to the Laos sample in the MDS plot were the three "highlander" Southern Sino-Tibetan groups (Southern Tibeto-Burmans [4], Southern [6] and Mixed Han [7]), while other "highlander", the Hmong and Mien [5], appeared far from the Laos sample. This might reflect expanding Sino-Tibetan tribes immigrating from the Northwest of MSEA, and is in agreement with the reported migration routes (see above). Both in the shared haplotypes analysis (see Additional File 7) and the MDS plot (see Figure 4), there was only small evidence for admixture by
Northern Sino-Tibetan groups (Tibet [4] and North Han [6]), suggesting that these migrations were minor concerning the area of today's Laos or blurred by the admixture by indigenous females to immigrating Northern groups (as reported for the Southern Han [6]). Specific, but limited Northern traces were found in the Laos sample, however (haplogroups D, M8 and C7, see above).

\section{Conclusion}

The cross-sectional Laotian sample presented here is highly suitable for genetic purposes regarding the countrywide mtDNA variation. Subpopulation and regional databases for detailed population genetic investigations and reliable forensic frequency estimates are desirable and need more extensive sampling. New phylogenetic lineages were detected: this sample will significantly contribute to further clarification of the Southeast Asian mtDNA phylogeny and the development of region specific filters for NETWORK constructions $[19,20]$. The limited $\operatorname{cod} R$ sequence analysis considerably increased phylogenetic resolution, suggesting that complete mitochondrial genome sequencing and analyzing a greater number of samples and populations will help to identify additional new lineages, yielding a more realistic picture of human mtDNA diversity, dispersal history and a higher power of discrimination for forensic purposes.

This first Laos dataset reveals a highly diverse population in terms of mtDNA composition, possibly reflecting the contribution of several major ethnolinguistic groups and a complex migration history. The Laotian population sample showed to be highly differentiated and lies well amid other Southeast Asian populations in terms of haplogroup structure, diversity indices and sharing of haplotypes. Nevertheless, its genetic structure was significantly different from 15 East Asian groups included in the comparisons. Our sample gives strong indication for a mixed Southeast Asian aboriginal origin of the extant Laos population along with limited Northern East Asian contributions, with highest similarity to Austro-Asiatic and Southern Sino-Tibetan populations. This finding was unexpected, as the Daic are culturally dominant in Laos, but is in agreement with the ethnic divisions of Southeast Asia before the Han expansions, where the Austro-Asiatic lived in this central area of today's Laos [3]. However, this mtDNA study reflecting the maternal history of Laos is only one piece of the puzzle. Y-chromosomal and autosomal markers will allow further, and possibly contrary, insights into the complex migration and population history of Laos and Southeast Asia [40,41].

The haplotypes presented in this study will be available on the EMPOP database http://www.empop.org [EMPOP: EMP00083] and on GenBank [GenBank:HM852213HM852426] upon publication. This publication follows 
the recommendations of the International Society of Forensic Genetics on the use of mtDNA in forensic analyses.

\section{Additional material}

\section{Additional file 1: Donor provenience list. The Laos province of birth is} given for every donor.

Additional file 2: Quasi-median network portraits from 214 mtDNA control regions from Laos. Network torsos of HVS-I (nps 16024-16569; part A) and HVS-II (nps 1-576; part B). Condensed and filtered haplotypes are represented by the nodes, their haplogroup and number is indicated. Prehaplogroups are denoted as haplogroups. A plus sign indicates that haplotypes of several haplogroups have been condensed in that node. Transitions are marked in green, transversions in red.

Additional file 3: Interpretation of quasi-median networks from 214 mtDNA control regions from Laos. In this file, the networks in Additional file 2 are explained.

Additional file 4: MtDNA polymorphisms of the 214 samples from Laos. The analyzed range, haplotype (as full list of differences to the revised Cambridge Reference Sequence [16]) and haplogroup of every sample are given. Haplogroups according to [18], release 8.

Additional file 5: Refined phylogeny of haplogroup B4e. This modified CR phylogeny is indicated by five samples from Laos, Vietnam [23], Hong Kong [24] and Japan [31]. The tree is rooted in haplogroup B4. Haplogroups according to [18], release 8.

Additional file 6: AMOVA results for five East Asian populations (analyzed range: nps 16024-16497 30-407). Part A: Design and results of AMOVA. Part B: Population average pairwise differences. Part C: $F_{S T}$ comparison among populations. References: this study, [7,17,23,24]

Additional file 7: Shared haplotypes within the Laos population sample. Only one example haplotype is indicated per shared haplotype. Part A: comparison with four East Asian populations (nps 16024-16497 30-407). Part B: comparison with 16 East Asian populations (nps 1602416383). References: this study, [3-7,12,17,23-26].

Additional file 8: AMOVA results for 17 East Asian populations (analyzed range: nps 16024-16383). Part A: Design and results of AMOVA. Part B: Population average pairwise differences. Part C: $F_{S T}$ comparison among populations. References: this study, [3-7,12,17,23-26].

\section{List of abbreviations used}

AMOVA: analysis of molecular variance; $C R$ : control region (of the mtDNA); codR: coding region (of the mtDNA); d.f: degrees of freedom; HVS: hypervariable segment; KYBP: thousand years before present; MDS: multidimensional scaling; MPD: mean pairwise differences; MSEA: Mainland Southeast Asia; mtDNA: mitochondrial DNA; np: nucleotide pair; RMP: random match probability; SNP: single nucleotide polymorphism; STR: short tandem repeat.

\section{Acknowledgements}

The authors are indebted to all who donated their DNA for this study. They wish to thank Daniela Niederwieser, Alexandra Lindinger and Gabriela Huber for excellent technical assistance along with Liane Fendt (all: Institute of Legal Medicine, Innsbruck Medical University) and Jodi A. Irwin (Armed Forces DNA Identification Laboratory, Rockville, MD, USA) for meaningful discussion. The authors are grateful to the reviewers for their helpful comments. Arnold Obermayr and colleagues from the Austrian embassy to Thailand, Laos, Myanmar and Cambodia in Bangkok provided valuable information on the country. This work was supported by the Austrian Science Fund (FWF) Translational Research Program (project L397).

\section{Author details}

${ }^{1}$ Institute of Legal Medicine, Innsbruck Medical University, Müllerstrasse 44, Innsbruck, Austria. Institute of Mathematics, University of Innsbruck, Technikerstrasse 13, Innsbruck, Austria. ${ }^{3}$ Division of Genetic Epidemiology, Department of Medical Genetics, Molecular and Clinical Pharmacology, Innsbruck Medical University, Schöpfstrasse 41, Innsbruck, Austria.
${ }^{4}$ Pathologisches Institut, Ludwig-Maximilians-Universität, Munich, Germany. ${ }^{5}$ Department of Dermatology, Columbia University, New York, NY, USA. ${ }^{6}$ National University of Laos, Vientiane, Laos. ${ }^{7}$ Department of Pediatrics, Chiang Mai University, Chiang Mai, Thailand. Institut für Humangenetik, Universität Münster, Münster, Germany. ${ }^{9}$ Institute of Legal Medicine, University of Cologne, Melatengürtel 60-62, Cologne, Germany.

\section{Authors' contributions}

MB designed and conducted experiments, retrieved data, performed calculations, interpreted results and conceived and wrote the manuscript. BZ conducted experiments, interpreted results and contributed to the manuscript. AR retrieved data, performed calculations, interpreted results and contributed to writing and editing the manuscript. AK helped in organizing DNA samples and contributed to the manuscript. DH, BH, SS, TS and JH helped in conceiving the study, organized DNA samples, performed DNA extractions and contributed to the manuscript. TK performed laboratory work and contributed to the manuscript. PS provided data and contributed to the manuscript. WP conceived and coordinated the entire project, supervised experiments, interpreted and validated results and contributed to writing and editing the manuscript. All authors approved the final version of the manuscript.

Received: 2 August 2010 Accepted: 18 February 2011 Published: 18 February 2011

\section{References}

1. Baird IG: Laos. In The Indigenous World 2009. Edited by: Wessendorf K. Copenhagen: International Work Group for Indigenous Affairs (IWGIA); 2009:359-366 [http://iwgia.org/sw16164.asp].

2. Enfield NJ: Areal linguistics and Mainland Southeast Asia. Annu Rev Anthropol 2005, 34:181-206.

3. Li H, Cai X, Winograd-Cort ER, Wen B, Cheng X, Qin Z, Liu W, Liu Y, Pan S, Qian J, Tan CC, Jin L: Mitochondrial DNA diversity and population differentiation in southern East Asia. Am J Phys Anthropol 2007, 134:481-488.

4. Wen B, Xie X, Gao S, Li H, Shi H, Song X, Qian T, Xiao C, Jin J, Su B, Lu D, Chakraborty R, Jin L: Analyses of genetic structure of Tibeto-Burman populations reveals sex-biased admixture in southern Tibeto-Burmans. Am J Hum Genet 2004, 74:856-865.

5. Wen B, Li H, Gao S, Mao X, Gao Y, Li F, Zhang F, He Y, Dong Y, Zhang Y, Huang W, Jin J, Xiao C, Lu D, Chakraborty R, Su B, Deka R, Jin L: Genetic structure of Hmong-Mien speaking populations in East Asia as revealed by mtDNA lineages. Mol Biol Evol 2005, 22:725-734.

6. Wen B, Li H, Lu D, Song X, Zhang F, He Y, Li F, Gao Y, Mao X, Zhang L, Qian J, Tan J, Jin J, Huang W, Deka R, Su B, Chakraborty R, Jin L: Genetic evidence supports demic diffusion of Han culture. Nature 2004, 431:302-305.

7. Yao YG, Kong QP, Bandelt HJ, Kivisild T, Zhang YP: Phylogeographic differentiation of mitochondrial DNA in Han Chinese. Am J Hum Genet 2002, 70:635-651.

8. Blench R: Stratification in the peopling of China: How far does the linguistic evidence match genetics and archaeology? In Past Human Migrations in East Asia: Matching archaeology, linguistics and genetics. Edited by: Sanchez-Mazas A, Blench R, Ross MD, Peiros I, Lin M. Abingdon and New York: Routledge; 2008:105-132, [Routledge Studies in the Early History of Asia].

9. Enfield NJ: Language and Culture in Laos: An Agenda for Research. The Journal of Lao Studies 2010, 1:48-54.

10. Yokoyama S: The Situation of Ethnic Minorities in Laos. In Lao Health Master Planning Study, Progress Report I. Edited by: Ministry of Health and JICA Study Team. Vientiane: Ministry of Health; 2001:A6.1-A6.8.

11. Chapter 28: Ethnic Groups in Laos. News Bulletin for November-December 1997 of the Embassy of the Lao People's Democratic Republic, Washington, DC, USA 1997

12. Gan RJ, Pan SL, Mustavich LF, Qin ZD, Cai XY, Qian J, Liu CW, Peng JH, Li SL, XU JS, Jin L, Li H, The Genographic Consortium: Pinghua population as an exception of Han Chinese's coherent genetic structure. J Hum Genet 2008, 53:303-313.

13. Miller SA, Dykes DD, Polesky HF: A simple salting out procedure for extracting DNA from human nucleated cells. Nucleic Acids Res 1988, 16:1215.

14. Parson W, Bandelt HJ: Extended guidelines for mtDNA typing of population data in forensic science. Forensic Sci Int Genet 2007, 1:13-19. 
15. Bandelt HJ, Parson W: Consistent treatment of length variants in the human mtDNA control region: a reappraisal. Int I Legal Med 2008, 122:11-21.

16. Andrews RM, Kubacka I, Chinnery PF, Lightowlers RN, Turnbull DM, Howell N: Reanalysis and revision of the Cambridge reference sequence for human mitochondrial DNA. Nat Genet 1999, 23:147.

17. Zimmermann B, Bodner M, Amory S, Fendt L, Röck A, Horst D, Horst B, Sanguansermsri T, Parson W, Brandstätter A: Forensic and phylogeographic characterization of mtDNA lineages from northern Thailand (Chiang Mai). Int J Legal Med 2009, 123:495-501.

18. van Oven $M$, Kayser $M$ : Updated comprehensive phylogenetic tree of global human mitochondrial DNA variation. Hum Mutat 2009, 30: E386-E394.

19. Bandelt HJ, Dür A: Translating DNA data tables into quasi-median networks for parsimony analysis and error detection. Mol Phylogenet Evol 2007, 42:256-271.

20. Parson W, Dür A: EMPOP-a forensic mtDNA database. Forensic Sci Int Genet 2007, 1:88-92

21. Brandstätter A, Klein R, Duftner N, Wiegand P, Parson W: Application of a quasimedian network analysis for the visualization of character conflicts to a population sample of mitochondrial DNA control region sequences from southern Germany (UIm). Int I Legal Med 2006, 120:310-314.

22. Bodner M, Irwin JA, Coble MD, Parson W: Inspecting close maternal relatedness: towards better mtDNA population samples in forensic databases. Forensic Sci Int Genet.

23. Irwin JA, Saunier JL, Strouss KM, Diegoli TM, Sturk KA, O'Callaghan JE, Paintner CD, Hohoff C, Brinkmann B, Parsons TJ: Mitochondrial control region sequences from a Vietnamese population sample. Int I Legal Med 2008, 122:257-259

24. Irwin JA, Saunier JL, Beh P, Strouss KM, Paintner CD, Parsons TJ: Mitochondrial DNA control region variation in a population sample from Hong Kong, China. Forensic Sci Int Genet 2009, 3:e119-e125.

25. Chen F, Wang SY, Zhang RZ, Hu YH, Gao GF, Liu YH, Kong QP: Analysis of mitochondrial DNA polymorphisms in Guangdong Han Chinese. Forensic Sci Int Genet 2008, 2:150-153.

26. Hill C, Soares P, Mormina M, Macaulay V, Clarke D, Blumbach PB, VizueteForster M, Forster P, Bulbeck D, Oppenheimer S, Richards M: A mitochondrial stratigraphy for Island Southeast Asia. Am J Hum Genet 2007, 80:29-43.

27. Excoffier L, Lischer HEL: Arlequin suite ver 3.5: a new series of programs to perform population genetics analyses under Linux and Windows. Molecular Ecology Resources 2010, 10:564-567.

28. Irwin JA, Saunier JL, Niederstätter H, Strouss KM, Sturk KA, Diegoli TM, Brandstätter A, Parson W, Parsons TJ: Investigation of heteroplasmy in the human mitochondrial DNA control region: a synthesis of observations from more than 5000 global population samples. J Mol Evol 2009, 68:516-527.

29. Kong QP, Bandelt HJ, Sun C, Yao YG, Salas A, Achilli A, Wang CY, Zhong L, Zhu CL, Wu SF, Torroni A, Zhang YP: Updating the East Asian mtDNA phylogeny: a prerequisite for the identification of pathogenic mutations. Hum Mol Genet 2006, 15:2076-2086.

30. Irwin JA, Ikramov A, Saunier J, Bodner M, Amory S, Röck A, O'Callaghan J, Nuritdinov A, Atakhodjaev S, Mukhamedov R, Parson W, Parsons TJ: The mtDNA composition of Uzbekistan: a microcosm of Central Asian patterns. Int J Legal Med 2010, 124:195-204.

31. Tanaka M, Cabrera VM, Gonzalez AM, Larruga JM, Takeyasu T, Fuku N, Guo L, Hirose R, Fujita Y, Kurata M, Shinoda K, Umetsu K, Yamada Y, Oshida Y, Sato Y, Hattori N, Mizuno Y, Arai Y, Hirose N, Ohta S, Ogawa O, Tanaka Y, Kawamori R, Shamoto-Nagai M, Maruyama W, Shimokata H, Suzuki R, Shimodaira $\mathrm{H}$ : Mitochondrial genome variation in eastern Asia and the peopling of Japan. Genome Res 2004, 14:1832-1850.

32. Tabbada KA, Trejaut J, Loo JH, Chen YM, Lin M, Mirazon-Lahr M, Kivisild T, De Ungria MC: Philippine mitochondrial DNA diversity: a populated viaduct between Taiwan and Indonesia? Mol Biol Evol 2010, 27:21-31.

33. Chandrasekar A, Kumar S, Sreenath J, Sarkar BN, Urade BP, Mallick S, Bandopadhyay SS, Barua P, Barik SS, Basu D, Kiran U, Gangopadhyay P, Sahani R, Prasad BV, Gangopadhyay S, Lakshmi GR, Ravuri RR, Padmaja K Venugopal PN, Sharma MB, Rao VR: Updating phylogeny of mitochondrial DNA macrohaplogroup M in India: dispersal of modern human in South Asian corridor. PLOS ONE 2009, 4:e7447.
34. Wallace DC: A mitochondrial paradigm of metabolic and degenerative diseases, aging, and cancer: a dawn for evolutionary medicine. Annu Rev Genet 2005, 39:359-407.

35. Yao YG, Zhang YP: Phylogeographic analysis of mtDNA variation in four ethnic populations from Yunnan Province: new data and a reappraisal. $J$ Hum Genet 2002, 47:311-318.

36. Yao YG, Kong QP, Wang CY, Zhu CL, Zhang YP: Different matrilineal contributions to genetic structure of ethnic groups in the silk road region in China. Mol Biol Evol 2004, 21:2265-2280.

37. Metspalu M, Kivisild T, Bandelt HJ, Richards M, Villems R: The pioneer settlement of modern humans in Asia. In Human Mitochondrial DNA and the Evolution of Homo sapiens. Edited by: Bandelt HJ, Macaulay V, Richards M. Berlin and Heidelberg: Springer; 2006:181-199, [Gross HJ, Bujnicki JM (Series Editors): Nucleic Acids and Molecular Biology, vol 18.].

38. Macaulay V, Hill C, Achilli A, Rengo C, Clarke D, Meehan W, Blackburn J, Semino O, Scozzari R, Cruciani F, Taha A, Shaari NK, Raja JM, Ismail P, Zainuddin Z, Goodwin W, Bulbeck D, Bandelt HJ, Oppenheimer S, Torroni A, Richards M: Single, rapid coastal settlement of Asia revealed by analysis of complete mitochondrial genomes. Science 2005, 308:1034-1036.

39. Bradley D: Mainland Southeast Asia. In Sociolinguistics: an International Handbook of the Science of Language and Society. 2 edition. Edited by: Ammon U, Dittmar N, Mattheier KJ, Trudgill P. Berlin and New York: Walter de Gruyter; 2006:2007-2013, [Wiegand HE (Series Editor): Handbooks of Linguistics and Communication Science, vol 3.].

40. The HUGO Pan-Asian SNP Consortium, Abdulla MA, Ahmed I, Assawamakin A, Bhak J, Brahmachari SK, Calacal GC, Chaurasia A, Chen CH, Chen J, Chen YT, Chu J, Cutiongco-de la Paz EM, De Ungria MC, Delfin FC, Edo J, Fuchareon S, Ghang H, Gojobori T, Han J, Ho SF, Hoh BP, Huang W, Inoko $H$, Jha $P$, Jinam $T A$, Jin L, Jung J, Kangwanpong D, Kampuansai J, et al: Mapping human genetic diversity in Asia. Science 2009, 326:1541-1545.

41. Stoneking M, Delfin F: The human genetic history of East Asia: weaving a complex tapestry. Curr Biol 2010, 20:R188-193.

42. Bandelt HJ, Quintana-Murci L, Salas A, Macaulay V: The fingerprint of phantom mutations in mitochondrial DNA data. Am J Hum Genet 2002, 71:1150-1160.

doi:10.1186/1471-2148-11-49

Cite this article as: Bodner et al.: Southeast Asian diversity: first insights into the complex mtDNA structure of Laos. BMC Evolutionary Biology 2011 11:49.

\section{Submit your next manuscript to BioMed Central and take full advantage of:}

- Convenient online submission

- Thorough peer review

- No space constraints or color figure charges

- Immediate publication on acceptance

- Inclusion in PubMed, CAS, Scopus and Google Scholar

- Research which is freely available for redistribution

Submit your manuscript at www.biomedcentral.com/submit
C Biomed Central 